\title{
MODES OF INBOUND KNOWLEDGE FLOWS: ARE COOPERATION AND \\ OUTSOURCING REALLY COMPLEMENTARY?
}

Elena M. Gimenez Fernandez*

Complutense University of Madrid

Francesco D. Sandulli

Complutense University of Madrid

\section{Abstract}

This study examines the relationship between breadths of two different modes of external knowledge: R\&D outsourcing and cooperation. Building upon transaction costs literature and literature on research partner breadth and R\&D outsourcing we hypothesize an U-inverted relationship between outsourcing breadth and innovation performance and a complementary relationship between $R \& D$ outsourcing and $R \& D$ cooperation. The model is tested on a large sample based on CIS survey for Spain. The empirical analysis confirms the U-inverted relationship between outsourcing breadth and innovation but also reveals an interesting result: the complementary effect of $R \& D$ cooperation varies with the level of $R \& D$ outsourcing breadth and it is not confirmed for low and medium levels of R\&D outsourcing breadth. The results have important implications for theory on the selection of different modes of inbound open innovation and for managers and their cooperation and outsourcing strategies.

Key words

Open innovation; cooperation breadth; R\&D outsourcing breadth; innovative performance; OI combination

*Corresponding author: elegimen@ucm.es 


\section{MODES OF INBOUND KNOWLEDGE FLOWS: ARE COOPERATION AND OUTSOURCING REALLY COMPLEMENTARY?}

\section{Introduction}

This study analyzes the impact of R\&D outsourcing breadth, as well as the moderator effect of cooperation on innovation performance. R\&D outsourcing and cooperation are two different strategies to integrate external technology. R\&D Outsourcing is usually performed to reduce costs, reinforce specialization, and achieve economies of scale, while collaboration is motivated by strategic rather than cost considerations (Gooroochurn and Hanley 2007; Narula 2001). As a result, outsourcing, compared to collaboration, is less common in basic research (Andries and Thorwarth 2014), and is frequently used in non-core activities where knowledge is explicit and less complex (Spithoven and Teirlinck 2015; Weigelt 2009), and for more incremental innovation (Stanko and Olleros 2013). We believe that it is essential to examine the dynamic between outsourcing and cooperation strategies, taking into account their different natures and goals.

Most of the research has examined the 'make' or 'buy' trade-off and the complementarity or substitutability between internal and external R\&D (Andries and Thorwarth 2014; Audretsch, Menkveld and Thurik 1996; Berchicci 2013; Lokshin, Belderbos and Carree 2008; Hagedoorn and Wang 2012; Love and Roper 2001, 2009; McIvor 2009; Piga and Vivarelli 2003, 2004; Schmiedeberg 2008; Veugelers and Cassiman 1999). While valuable, this strand of research does not answer several questions related to the best selection models to define the inbound open innovation strategy for external knowledge.

Open Innovation (OI) has been defined as 'a distributed innovation process based on purposively managed knowledge flows across organizational boundaries, using pecuniary and non-pecuniary mechanisms in line with the organization's business model' (Chesbrough and 
Bogers 2014:17). Accordingly, different openness strategies constitute the OI paradigm (Dahlander and Gann 2010). Among these strategies, outsourcing and cooperation play key roles in inbound flows of knowledge and in-bound OI.

A number of papers have analyzed $R \& D$ outsourcing and $R \& D$ cooperation in a common framework (Dhont-Peltraut and Pfister 2011; Holl and Rama 2014; Tsai and Wang 2008, 2009), but they do not consider the interrelation between these strategies. Firms frequently combine these two modes of in-bound OI and only some scholars have examining the complementarities of R\&D cooperation and R\&D outsourcing (Grimpe and Kaiser 2010; Lin, Hsiao and Lin 2013; Teirlinck and Spithoven 2011, 2013), considering it from different perspectives. For example, while Grimpe and Kaiser (2010) focused on external resources from partner variety and experience; Teirlinck and Spithoven $(2011,2013)$ analyzed firms' internal resources in terms of research managers and R\&D experts; and Lin et al. (2013) made a methodological contribution by considering a method that combined adoption and productivity approaches. Though much progress has been made, research comparing different modes of in-bound OI still has a long way to go (Bahemia and Squire 2010).

This research explores this comparatively underexplored research field by focusing on $R \& D$ cooperation and R\&D outsourcing, and underpinning the analysis of their complementarities through the concept of external knowledge source breadth. Breadth refers to the extent that 'firms access different external knowledge sources' (Zobel 2013: 68), such as customers, suppliers, competitors, universities, research centers, etc. Breadth is an essential part of literature studying the impact of inbound knowledge flows (Laursen and Salter 2006; Rothaermel and Deeds 2006; Bahemia and Squire 2010; Leiponen and Helfat 2010; Oerlemans, Knoben and Pretorius 2013; Collins and Riley 2013; Leeuw, Lokshin and Duysters 2014). Breadth has been mainly studied for cooperation activities, but it can be also conceptualized for R\&D outsourcing strategies. Some studies have considered the 
"broadness" of outsourcing by the number of different activities (Gilley and Rasheed 2000), but outsourcing breadth in terms of number of different external sources has barely been analyzed. Therefore, our first contribution is to analyze the impact of R\&D outsourcing on innovation performance by measuring it in the same manner as for cooperation, in terms of breadth.

Secondly, we study the moderator effect of cooperation breadth on the relationship between outsourcing breadth and the innovative performance of the firm. Our paper offers a new perspective with regard to the traditional 'buy', 'make' or 'ally' trade-off because we examine the effects of the interaction of two open innovation strategies - cooperation breadth and R\&D outsourcing breadth. This is important because firms may create mutual relational capital that generates synergies and economies of scale and scope. Because the paper focuses more on the learning process and relational capabilities arising from the exposure to different sources of knowledge, we do not consider sourcing depth.

We test our model on a large CIS data set of Spanish firms. This research uses pooled data from a longitudinal sample to evaluate the impact of different inbound OI strategies breadths on firm innovative performance. We found that there is a U-inverted relationship between outsourcing breadth and innovation performance and a complementary relationship between R\&D outsourcing and $R \& D$ cooperation, but that the complementary effect of $R \& D$ cooperation varies with the level of $R \& D$ outsourcing breadth, and is not confirmed for low and medium levels of R\&D outsourcing breadth.

The remainder of this paper is structured as follows. In the next section we review the theoretical background of inbound OI strategies, and we develop our hypotheses in Section 3. The fourth section describes methodology, and in the fifth section we present the statistical method and the results of our analyses. We then discuss our findings. We conclude with implications and directions for future research. 


\section{Literature background}

Theoretical literature has emphasized that different openness strategies exist. Dahnlander and Gann (2010) and Chesbrough and Bogers (2014) identified two main inbound strategies: sourcing and acquiring. Sourcing is a non-pecuniary type of openness, in which firms use and absorb external knowledge into their innovation processes; while acquiring is a pecuniary inbound innovation involving the acquisition of external knowledge, which is then integrated into the innovation process. In the same way, Tsai and Wang $(2008,2009)$ argued that there are two ways to access external technology: quasi-external activities such as technology cooperation, and fully external activities, i.e., market procurement, such as R\&D outsourcing and licensing.

R\&D outsourcing refers to the purchase by an enterprise of creative work performed by other enterprises or by public or private research organizations to increase the stock of knowledge for developing new and improved products and processes (OECD 2005). Consequently, the transformation of potential knowledge into realized knowledge is made by an external firm that transfers it together with its exploitation rights to the payer firm in the manner contractually specified (Grimpe and Kaiser 2010). Firms with few resources and looking for low risk and low cost knowledge exchange employ R\&D outsourcing (Gassmann, Enkel and Chesbrough 2010), and many firms tend to outsource non-core activities (Gilley and Raseed 2000; Mudambi and Tallman 2010; Narula 2001), as these activities are relatively standardized (Teirlinck and Spithoven 2013), involve explicit knowledge and entail low levels of complexity and uncertainty (Howells, Gagliardi and Malik 2008). R\&D outsourcing is considered the most basic inbound OI strategy. Firms do not enter into long relationships with the R\&D suppliers but temporary contracts for a previously specified purpose (Grimpe and Kaiser 2010), where firms can change suppliers when new or cost-effective technologies are 
available in the market (Gilley and Rasheed 2000). Although firms that incorporate outsourced knowledge into their innovation processes may encounter coordination and communication challenges arising from R\&D outsourcing activities (Tsai and Wang 2009), especially, if $\mathrm{R} \& \mathrm{D}$ outsourcing breadth increases, the interdependence between partners is minimum (Narula 2001).

Compared to R\&D outsourcing, collaboration is considered a more open strategy of knowledge sharing (Chesbrough, 2012; Teirlinck and Spithoven 2008), where knowledge exchange is more complex and tacit (Teirlinck and Spithoven 2013). R\&D cooperation usually focuses on a common project for a medium period of time, where partners share common objectives in the development of a specific technology (Hagedoorn 1993; Trombini and Comacchio 2012). Here, the transformation of valuable knowledge is made jointly by the firm and the partner, so a higher degree of learning is likely to occur (Fey and Birkinshaw 2005). The governance cost of the 'ally' mode is higher than the 'buy' mode because cooperation involves specialized assets (Williamson 1991). In addition, the opportunity cost of cooperation is potentially higher than in $R \& D$ outsourcing because the $R \& D$ outcome is uncertain (Holmstrom 1989) and firms cannot observe partners behavior (Oxley 1997), who are often engaged in attempts to outlearn each other (Khanna, Gulati and Nohria 1998) since knowledge-based assets are imperfectly protected (Cohen, Nelson and Walsh 2002). To succeed in joint innovation, improve firm performance and ensure survival chances (Mitsuhashi and Greve 2009), firm's technologies or knowledge bases must 'fit' (Baum, Cowan and Jonard. 2010). Cooperation and R\&D outsourcing differs in terms of availability and training of research managers and R\&D experts (Teirlinck and Spithoven 2013). Cooperation may require more advanced management capabilities (Lane and Lubatkin 1998), and it changes the internal cost structure of the firm (Kale and Singh 2009). Table 1 summarizes the differences between $R \& D$ outsourcing and cooperation. 


\section{Conceptual framework and hypotheses}

\subsection{R\&D outsourcing breadth}

Openness breadth refers to the extent to which 'firms access different external knowledge sources', such as customers, suppliers, competitors, universities, research centers, etc. (Zobel 2013: 68). However, this dimension has been unexplored in outsourcing empirical literature. Various scholars have pointed to the existence of a curvilinear relationship (inverted U-shape) between outsourcing intensity and firm performance (Kotabe and Mol 2009; Kotabe, Mol, Murray and Parente 2012; Leachman, Pegels and Shin 2005; Rothaermel, Hitt and Jobe 2006; Grimpe and Kaiser 2010; Berchicci 2013). Focusing on innovation literature, Grimpe and Kaiser (2010) studied the benefits and challenges of R\&D outsourcing, discovering an inverse U-shaped relationship between R\&D outsourcing and innovation performance. They argued that the effects of $R \& D$ outsourcing on innovation performance is initially positive because it allows access to valuable resources not available internally, fostering greater efficiency, lowering costs and boosting their innovation processes. However, with greater intensities of R\&D outsourcing, the returns from additional $R \& D$ outsourcing become negative because of the dilution of firm-specific resources, the weakening of innovative capabilities, and the increasing need for management attention. Berchicci (2013) also noted that R\&D outsourcing is positively related to innovation performance but only up to a point, because excessive outsourcing increases search, coordinating and monitoring costs and could generate a risk of external knowledge dependence. Graphically speaking, this implies that the benefits of outsourcing intensity on innovation creates an inverted U-shape. In these studies, R\&D outsourcing has been measured in different ways, such as R\&D external expenditures (Grimpe and Kaiser 2010) or number of activities (Berchicci 2013). 
We extend that strand of research and consider that outsourcing breadth is likely to have an effect on the performance of the firm's overall OI strategy. Prior research has shown that knowledge search breadth brings greater innovation (Rothaermel and Deeds 2006; Bahemia and Squire 2010; Leiponen and Helfat 2010; Zobel 2013) because it pools the efforts of diverse knowledge sources and it enhances the potential for new products and a better matching of products and consumer preferences (Almirall and Casadesus-Masanell 2010). Some studies have also shown that performance decreases when firms open their innovation process to many external knowledge sources (Laursen and Salter 2006; Rothaermel and Deeds 2006). We propose that an inverted U-shaped relationship exists between R\&D outsourcing breadth and firms' innovative performance.

The benefits of R\&D outsourcing breadth can be summarized through Cui, Loch, Grosmann and He (2012)'s motivations to outsource: (1) economical motivation to reduce internal R\&D investment (factory and premise costs) (2) industrial motivation, as outsourcing decreases firms' innovative processes cadence and market cycle; (3) market motivation as outsourcing breadth could open new markets or lead to better understanding of current market needs; (4) technological motivation since a greater variety of outsourcing firms provides new technologies with the potential for radical innovations; (5) strategic motivation as non-core activities are outsourced to specialized outsourcers who know market regulations, standards and structures, so firms are able to focus on their core competencies; and (6) organizational motivation as increased outsourcing breadth reveals and overcomes internal barriers and rigidities, and encourages organizational change and innovation. However, increased outsourcing breadth also entails certain challenges. First, it is difficult to find the 'right' outsourcer (Tsai and Wang 2009) whose technology meets the firm's competitive strategy and is reliable (Hoecht and Trott 2006; Howells et al. 2008; Sen and MacPherson 2009). Second, communication problems increases with outsourcing breadth because firms may lack the 
expertise related to that area and being unable to communicate professionally with outsourcers. Third, outsourcers can sell their technologies to competitors (Tsai and Wang 2009) and extend them across the whole industry (Hoecht and Trott 2006), so it does not provide a competitive advantage for the firm. Finally, outsourcing breadth creates a risk of external dependency (Rothaermel et al. 2006) since firms acquire external technology rather than internally developing it (Tsai and Wang 2009; Wang, Roijjakers and Vanhaverbeke 2013), reducing their knowledge base in all areas and thereby damaging firms' absorptive capacity (Cohen and Levinthal 1990). Therefore, R\&D outsourcing breadth provides immediate access to different technologies and knowledge with few bureaucratic costs, reducing firms' innovative process time and the costs and risks of internal R\&D. However, higher levels of R\&D outsourcing breadth increase transaction costs and the risks of depending on external outsourcers. Hence, we propose that:

Hypothesis 1: There is an inverted $U$-shaped relationship between $R \& D$ outsourcing breadth and innovation performance.

\subsection{The moderator role of cooperation}

The impact of cooperation on innovation performance has received considerable attention in literature. Apart from the direct effect of cooperation breadth on the chances of positive innovation outcomes (Chesbrough and Appleyard 2007; Leiponen and Helfat 2010; Zobel 2013), we expect cooperation to have moderating effects on the relationship between $R \& D$ outsourcing breadth and firms' innovation performance. In this paper we are specifically interested in the effect of the joint adoption of cooperation breadth and R\&D outsourcing breadth on innovation performance.

Over the last years, Transaction Costs Economy (TCE) and the Resource-based view (RBV) have converged somewhat in the explanation of knowledge flows because of their 
complementary roles and co-evolution (Spithoven and Teirlinck 2015). Basing our arguments on TCE and RBV, we consider that cooperation moderates the relationship between R\&D outsourcing and innovation performance through two mechanisms: absorptive capacity and relational capability. Our framework weights the balance between transaction costs and asset specificity, and the type of knowledge transferred and mutual learning. Figure 1 illustrates these quantities and places OI strategies in a matrix.

\section{Figure 1 about here}

First, cooperation might help to absorb the knowledge from contracts, generating new recombinations. The potential for new recombinations is based on the idea of taper integration, developed by Rothaermel et al. (2006), who affirmed that a firm creates synergy through simultaneously accomplishing vertical integration and strategic outsourcing. As a result, taper integration may reduce transaction costs, enhance strategic flexibility, increase access to diverse sources of knowledge, integrate tacit knowledge and complementary assets, and thereby enhance the development of new products and increases a firm's product portfolio. Grimpe and Kaiser (2010) argued that cooperation may mitigate the negative effects from over-outsourcing on innovation performance. One reason for that behavior was partner variety, which increases the likelihood of accessing novel and unique knowledge that could be redeployed within a firm. Since each OI strategy has its unique advantages and drawbacks, an adequate combination will enhance firms' flexibility and innovation (Spithoven and Teirlinck 2015). Thus, a base of $R \& D$ from cooperation, do not fully eliminate the risk of external dependence and it may create new recombinations since different types of knowledge are combined, suggesting a complementary effect between OI breadth strategies.

Second, cooperation breadth generates an external relationship management capability-a 'relational capital' that can mitigate the problems of contract formation. Many firms invest in specific assets to manage cooperative activities, creating a dedicated alliance management 
department (Kale, Dyer and Singh 2002; Kale and Singh 2007, 2009; Sampson 2005; Schilke and Goerzen 2010), or a specific committee consisting of members of each part of a collaborative agreement (Hagedoorn and Hesen 2007). In this regard, another reason for the positive moderator role of cooperation, according to Grimpe and Kaiser (2010), is increased experience, as the experience of collaborating with a large variety of partners facilitates the interactions with outsourcers and makes firms recognize superior resource deployments more easily. The synergetic effect between OI breadth strategies comes up when a high degree of partner diversity is used by both strategies. The potential for misunderstanding and costly miscommunication is mitigated as firms get more experience in $R \& D$ outsourcing and cooperation.

Firms create a relational capital that can be used by both strategies. The relational capital provided by cooperative activities, which are based on mutual trust and interaction and curb opportunistic and disloyal behaviors (Gulati 1998), creates a basis for learning and know-how transfer (Kale, Singh and Perlmutter 2000) that facilitates external knowledge acquisitions. Poppo and Zenger (2002) assert that the interdependence between partners as a consequence of a relational governance improves the exchange outcome. When combining cooperation breadth with $\mathrm{R} \& \mathrm{D}$ outsourcing breadth, firms could benefit from economies of scale and scope.

Overall, combining R\&D outsourcing breadth with cooperation could contribute to the adoption of economies of scale and scope in building relational capital, at the same time that using both breadth strategies enhances the likelihood of new combinations. Thus, cooperation breadth positively moderates the relationship between $\mathrm{R} \& \mathrm{D}$ outsourcing breadth and innovation performance, avoiding the negative effects of over-openness in R\&D outsourcing:

Hypothesis 2: The relationship between $R \& D$ outsourcing breadth and innovation performance is positively moderated by cooperation breadth. 


\section{Methodology}

\subsection{Sample}

We test our model on a representative sample of Spanish firms from the database Spanish Technological Innovation Panel (PITEC), collected by the Spanish National Statistics Institute (INE). The survey was implemented in 2003 and it is based on the annual Spanish responses to the Community Innovation Survey (CIS), whose method and types of questions are described in Oslo Manual (OECD 2005). CIS data has been used in numerous academic papers across Europe, for example, in Germany (Grimpe and Kaiser 2010), Belgium (Cassiman and Veugelers 2002, 2006; Spithoven, Clarysse and Knockaert 2011), the United Kingdom (Laursen and Salter 2006); and in other non-European countries, such as Taiwan (Tsai and Hsieh 2009; Tsai and Wang 2009). In Spain, PITEC is a well-established research tool, and has been used in previous longitudinal studies (e.g., Escribano, Fosfuri and Tribó 2009; Sandulli, Fernandez-Menendez, Rodriguez-Duarte and Lopez-Sanchez 2012; Un, Cuervo-Cazurra and Asakawa 2010; Vega-Jurado, Manjarrés-Henríquez and Gutiérrez-Gracia 2010).

The database has broad sector coverage, and includes both manufacturing and service sectors. PITEC divides these industries according to the standard National Classification of Economic Activities (CNAE) code, using a two-digit code, except when there are many firms in an industry and the firm's activity is defined at three digits or when there are just a few firms, in which case activities are regrouped with others.

In the survey, firms are asked to indicate whether they have been able to achieve a product innovation. Product innovation include both technologically new products, which refer to 'goods and services that differ significantly in their characteristics or intended uses from products previously produced by the firm' (OECD 2005:48); and technologically improved products, which 'occur through changes in materials, components and other characteristics 
that enhance performance' (OECD 2005:48). The questionnaire asks then firms to assert what share of their sales can be ascribed to innovations new to the market and which are new to the firm. In the questionnaire there are a series of questions about external acquisition of technology and the sources of knowledge for innovation. In 2004 PITEC introduced some changes in the questionnaire, affecting variables related to cooperation and external sources for technology innovation, which are central variables in our model. Due to these limitations, in our study we have not considered the data from the 2003 survey, and use only pooled longitudinal data from 2004 to 2012. We have used pooled data instead of panel data because maximum likelihood estimations - used for the Tobit analysis- might introduce biases (Lopez 2011). In addition, observations produce change due to mergers, disclosure, etc., that could mislead (Baum and Silverman 2004; Teirlinck, Dumon and Spithoven 2010). In total, and due to some missing data, we consider a subsample of 61,434 observations.

\subsection{Measures}

\section{Dependent variable}

Though there are different forms through which firm innovation performance can be assessed, we use product innovation as a proxy to indicate the innovative performance by firms as it has been traditionally used in literature (Belderbos, Carree and Lokshin 2004; Faems, van Looy and Debackere 2005; Faems, de Visser, Andries and van Looy 2010; Nieto and Santamaria 2007). We measure product innovation performance (Newprod) as proportion relative to the turnover of new or strongly improved products that the company introduced to the market and that were new to the market or to the firm. New products to the market or to the firm are mutually exclusive since they add up to $100 \%$, so Newprod ranges from 0 to 100 .

\section{Independent variables}


Our study analyzes the impact of two inbound OI strategies on the innovation performance of the firm: cooperation breadth and R\&D outsourcing breadth. First, cooperation breadth refers to agreements with a diversity of external sources - suppliers, customers, public sector customers, competitors, consultants, universities and research centers. We consider that partner diversity must be considered to measure cooperative agreements since it has been proven to have an impact on innovation performance (Laursen and Salter 2006; Oerlemans et al. 2013). Following the methodology of Laursen and Salter (2006), the variable cooperation breadth (coop) is constructed as the addition of seven sources of collaboration. Thus, each of the seven sources is coded as a binary variable, 0 being no use and 1 being use of the knowledge source. Subsequently, the seven sources are added up so that each firm gets a 0 when no collaboration sources are used, and a firm gets the value of 7 when all collaboration sources are used.

Second, in the survey, firms are asked whether they have acquired external $R \& D$, that is, if they have outsourced-in $R \& D$ technology. As cooperation, $R \& D$ outsourcing is also measured in terms of diversity of outsourcers. Thus, R\&D outsourcing breadth (out) is constructed as the addition of six sources of outsourcing: firms, research centers, public sector, universities, no governmental organizations, and other international organizations. Each of the six sources is coded as a binary variable, 0 being no use and 1 being use of the knowledge source. Again, the six sources are added up so that each firm gets a 0 when no outsourcing sources are used, and a firm gets the value of 6 when all outsourcing sources are used.

Considering the U-inverted shape of $R \& D$ outsourcing breadth, we square the variable outsourcing (out2). We include the interaction variables among cooperation breadth and R\&D outsourcing breadth (coop_out), and the interaction between cooperation breadth and R\&D 
outsourcing breadth squared (coop_out2) to test the impact of a joint adoption of these OI strategies on the innovation performance.

\section{$\underline{\text { Control variables }}$}

In order to rule out possible alternative explanations to those formally hypothesized, the model includes the following control variables. Previous research has discussed that firm age has a positive (Tsai et al. 2011; Wang et al. 2013) or negative (Wang and Li-Ying 2014) impact on innovation. To clarify inconsistent findings we include firm age (Logage), which is measured as the logarithm of the number of years between the foundation of the firm and the observation year. We also control for firm size (Logsize) as it has been argued to be relevant for firms' innovative behavior (Berchicci 2013; Cassiman and Veugelers 2002). This variable is measured by the logarithm of the total number of employees. As scholars consider internal R\&D to be crucial for innovation (Lin et al. 2013; Schmiedeberg 2008), we include firm's internal R\&D efforts (Intrd), measured as the proportion of its internal innovation expenses. Another input variable that might affect innovation performance is the firm's patent activity (Pat) (Faems et al. 2005). We measured it as a dummy variable that takes the value of 1 if the firm has applied for a patent. To reflect that our results are not simple reflecting $R \& D$ outsourcing intensity, but indeed the breadth of it, we include a control variable for R\&D outsourcing investment (Outintensity). It is measured as the share of R\&D external expenses. We have included a sector variable control (CNAE) to test if there are differences across manufacturing industry sectors since previous studies (Tsai 2009; Veugelers 1997; Wang et al. 2013) have indicated that it is necessary to correct the fixed industry effects. Finally, we have created dummy variables (Year) to control the possible bias of the observation year (Un et al. 2010; Wang et al. 2013). Controlling time-varying effects is necessary in a rapidly changing environment such as technology and innovation, and to check if the economic crisis 
impact on results. The year 2004 was the default. A short description of the variables used to test the model and their references are included in Table 2.

\section{Table 2 about here}

\section{Statistical method and results}

This study uses pooled data from 2004 to 2012 to test our hypothesis. Table 3 summarizes the number of observations included per year and it reports the basic statistics of the variables used in the analysis (except industry and year dummies). The data reveals interesting points. Along the nine-year period the firms' turnover from new or strongly improved products that were new to the market or to the firm (newprod) does not form a linear pattern but attained its maximum values from 2005 to 2010 and the lowest in 2004 and 2011-2012. The cooperation breadth variable (coop) increases throughout the period (from 0.79 to 1.02 ), excluding the year 2004, when it was higher (0.89) than for subsequent years. R\&D outsourcing breadth (out) was considerable higher in $2004(0.51)$ and quite similar through the rest of the periods (around 0.43). R\&D outsourcing intensity (outintensity) forms a similar pattern. It could be that firms are moving from $R \& D$ outsourcing to $R \& D$ cooperation, instead of looking for complementary behaviors. We also calculated means and standard deviations only for firms that stated they follow an open innovation strategy (not reported for the sake of brevity) and we found that due to the fact that many firms do not have any R\&D partner, our reported levels of breadth are low. If we only look to firms that reported cooperation breadth, the breadth average is 2.6; and for those which reported R\&D outsourcing breadth, the breadth average is 1.4. Correlation coefficients of the major variables used in the model are reported in Table 4.

Table 3 about here

Table 4 about here 
This study follows the procedure suggested by Friedrich (1982) to reduce or eliminate any bias resulting from multicollinearity because of interaction terms. This procedure first standardizes the independent variables, and then forms the cross-product terms. In addition, a VIF (variance inflation factor) test is used to evaluate the effect of multicollinearity. Only the VIF for the variable interaction variables exceed 10, but since it is constructed through the interaction of two standardized variables, we do not believe it contaminates our results; the VIFs for the rest of variables are smaller than 10 .

The econometric model that will be used to test the hypothesis is based on a (double) censored dependent variable - innovative performance - , which is measured as a percentage of turnover and therefore by definition ranges between 0 and 100, and a set of independent variables that represent OI strategies breadth and its interaction, and control variables. Following Laursen and Salter (2006), a censored Tobit model is applied. This model was proposed by James Tobin (1958) to estimate relationships between variables when there is either left- or right- censoring or both left-censored and right-censored in the dependent variable. In our case, the sample is both-side censored, the lower limit is 0 , and the upper limit 100 , since our dependent variable ranges between those values. Our latent model would be as follows:

$$
\begin{gathered}
y^{*}{ }_{i}=\text { Newprod }=\beta_{0}+\beta_{1} \text { Coop }+\beta_{2} \text { Out }+\beta_{3} \text { Out } 2+\beta_{4} \text { Coop } * \text { Out }+\beta_{5} \text { Coop } * \text { Out } 2+\beta_{6} \text { Age }+ \\
\beta_{7} \text { CNAEdummies }+\beta_{8} \text { Yeardummies }+\varepsilon, \varepsilon \sim N\left(0, \sigma^{2}\right)
\end{gathered}
$$

However, the assumption of normality of residuals in our model is not satisfied. To address this problem, Laursen and Salter (2006) assumed a lognormal distribution for the residuals of the Tobit model. We also apply this approach and we introduce a latent variable, lnnewprod, 
as a logarithmic transformation of an observed measure of product innovation, lnnewprod = $\ln (1+\text { newprod })^{1}$.

Sample selection poses a potential problem with this analysis and data, because we can only analyze those firms that answered the questionnaire. As a result, selective reporting may bias our results (Heckman 1979). We use Heckman selection model in two-steps to control for a possible sample selection bias in our continuous dependent variable. We first define a dependent variable with a dummy value: 1 if the firm made product innovations; 0 , if the firms did not make any new product. We then use the Probit model to estimate the model parameters, including our independent and control variables of the model, and a dummy variable indicating if the firm bought machinery, equipment and software, as corrected term. This latter variable could impact the introduction of new products to market as they are basic assets for the innovation process, but not in the amount of innovation because they are fixed assets. The process of this calculation is omitted for the sake of brevity. The inverse of Millsratio indicates that the null hypothesis is not significant at $95 \%$ of confidence $(\Upsilon=0.228$, $\mathrm{p}>0.05)$, thus our results do not suffer from sample-selection bias.

The results of the Tobit regression can be found in Table 5. First, we estimate Model I, which contains the control variables (for reasons of space we do not include all results from industry and year dummy variables in the table). Model II contains the direct effects of OI strategies breadth - cooperation and outsourcing — on product innovation. Finally, in Model III we introduce the interaction terms between the OI strategies breadth for different levels of outsourcing breadth.

The estimators of model II shows R\&D outsourcing breadth behavior, drawing an inverted-U shape related to innovation performance since the parameter for R\&D outsourcing breadth variable $($ Out $)$ is significant and positive $(\beta=0.402, \mathrm{p}<0.01)$, and the parameter for outsourcing

${ }^{1}$ Note: The lognormal transformation does not change the signs, nor the significance for the key variables' parameters in the subsequent estimations. 
squared (Out2) is significant as well and it is negative $(\beta=-0.288, \mathrm{p}<0.01)$. Hence, it supports our first hypothesis that there is an inverted U-shaped relationship between R\&D outsourcing breadth and innovation performance. We also verified that cooperation breadth is positively related to innovation performance $(\beta=0.345, \mathrm{p}<0.01)$ as suggested in the literature (Leiponen and Helfat 2010).

The estimation of Model III shows the interaction coefficients between cooperation breadth and $R \& D$ outsourcing breadth. We hypothesized that the relationship between $R \& D$ outsourcing breadth and innovation performance is positively moderated by cooperation breadth (Hypothesis 2). Our results show that between medium and high levels of R\&D outsourcing, the relationship between R\&D outsourcing breadth and innovation performance is positively moderated by cooperation breadth since the parameter Coop_Out2 is significant and positive $(\beta=0.049, \mathrm{p}<0.05)$, hence there are increasing returns to innovation performance. However, for low to medium levels of $R \& D$ outsourcing, the model reveals that the relationship between $\mathrm{R} \& \mathrm{D}$ outsourcing breadth and innovation performance is negatively moderated by cooperation breadth since the parameter Coop_Out is significant and negative ( $\beta=-0.111, \mathrm{p}<0.01)$; hence there are decreasing returns to innovation performance when both strategies are combined. Thereby, our hypothesis that cooperation positively moderates the relationship between $\mathrm{R} \& \mathrm{D}$ outsourcing breadth and innovation performance is partially confirmed.

\section{Table 5 about here}

Figure 2 shows interactive effect of R\&D outsourcing breadth and cooperation breadth on innovative performance for different levels of breadth. The chart shows that between low to medium levels of $R \& D$ outsourcing breadth, the contribution of cooperation breadth to innovation performance diminishes. It suggests that at this level of R\&D outsourcing breadth, the OI strategies analyzed are substitutes. In contrast, the figure shows that the contribution of 
cooperation breadth increases when the level of $R \& D$ outsourcing breadth is medium to high. Hence, cooperation breadth enhances innovation performance, suggesting that in this case, cooperation breadth and $R \& D$ outsourcing have complementary effects. These findings highlight the complexity of understanding the relationship between the breadths of different strategies of openness in shaping firms' innovative performance.

\section{Figure 2 about here}

Of our control variables, the age of the firm has a negative effect on innovation performance since along the three models its parameter (Logage) is significant and negative $(\beta=-0.199$, $\mathrm{p}<0.01, \beta=-0.187, \mathrm{p}<0.01$ and $\beta=-0.188, \mathrm{p}<0.01$, respectively). It suggests that older organizations may have greater resistance to new ideas. Applying for patents has a positive impact on innovation performance $(\beta=1.017, \mathrm{p}<0.01, \beta=0.817, \mathrm{p}<0.01$ and $\beta=0.815, \mathrm{p}<0.01$, respectively). The parameters for industry dummies are partially significant; in particular, there is a positive relationship with those related to textile and shoe industries, electronic equipment and information systems; and a negative relationship with plumbing industry and construction. Time effects may have an influence on innovation performance since year dummy coefficients are all significant and positive, except for 2012.

To ensure the robustness of the above findings, this study also runs different estimates for different samples (not reported for the sake of brevity). Because our sample includes data relative to some years after the financial crisis, we first exclude the initial year (2004) in our estimation, and then the final year (2012). The results of the Tobit regressions and the adjusted- $R^{2}$ and Chi-squared values indicate that the models fit to data $\left(\operatorname{adj}-\mathrm{R}^{2}=0.0311\right.$, $\chi^{2}=6230.54, \mathrm{p}<0.01 ;$ adj- $\mathrm{R}^{2}=0.0303, \quad \chi^{2}=6069.26, \mathrm{p}<0.01$, respectively); the estimated coefficients for outsourcing and outsourcing square are significant and show an U-inverted shape (out, $\beta=0.433, \mathrm{p}<0.01 ;$ out $, \beta=-0.278, \mathrm{p}<0.01 ; \beta=0.428, \mathrm{p}<0.01 ;$ out $2, \beta=-0.269$, $\mathrm{p}<0.01$, respectively), and the interaction effect are significant and their signs are the same as 
those presented in Table 5 (Coop_out, $\beta=-0.113, \mathrm{p}<0.01$; Coop_out2, $\beta=0.052, \mathrm{p}<0.05$; Coop_out, $\beta=-0.107, \mathrm{p}<0.01$; Coop_out $2, \beta=0.046, \mathrm{p}<0.05$, respectively).

We also checked the robustness of our results by running separate regressions for high-tech and low-tech sectors (Luker and Lyons 1997). Both models fit to data (adj- $\mathrm{R}^{2}=0.0155$, $\chi^{2}=499.70, \mathrm{p}<0.01 ; \operatorname{adj}-\mathrm{R}^{2}=0.0208, \chi^{2}=3901.60, \mathrm{p}<0.01$, respectively), and in both cases, outsourcing draws an inverted-U shape (out, $\beta=0.336, \mathrm{p}<0.01$; out2, $\beta=-0.218, \mathrm{p}<0.01$; $\beta=0.508, \mathrm{p}<0.01 ;$ out $2, \beta=-0.376, \mathrm{p}<0.01$, respectively), but we only found a significant interaction effect for low-tech firms (Coop_out, $\beta=-0.115, \mathrm{p}<0.01$; Coop_out2, $\beta=0.067$, $\mathrm{p}<0.01)$. This might be due to the fact that firms behave differently with respect to their outsourcing strategy. Thus, the impact of outsourcing breadth is stronger for low-tech firms, while this effect is flatter for high-tech companies, impeding the sharing of relational capital between $R \& D$ outsourcing and cooperation. This result is in line with previous literature as firms with higher R\&D capacity are better able to improve their innovative outcome through investing more in cooperation activities and relatively less in R\&D outsourcing (Berchicci 2013).

\section{Discussion}

The aim of this study was to analyze the impact of R\&D outsourcing breadth, as well as the moderator effect of cooperation on innovation performance. External knowledge sources are increasingly being used in firms' innovative processes (Laursen and Salter 2006). While most of literature has mainly studied breadth in cooperative activities (Collins and Riley 2013; Faems et al. 2005; Laursen and Salter 2006; Leeuw et al. 2014; Oerlemans et al. 2013; Rothaermel and Deeds 2006), this study evidenced that sourcing breadth can be also useful to analyze the impact of $R \& D$ outsourcing. Our results showed that there is an inverted Ushaped relationship between $R \& D$ outsourcing breadth and the innovation performance of a 
firm. It means it is beneficial for firms since it avoids risks about uncertain $R \& D$, decreases internal research costs and accelerates the innovation process (Baloh, Jha and Awazu 2008; Gilley and Rasheed 2000; Howells et al. 2008; Rundquist and Halila 2010; Tsai and Wang 2009). That said, investing too much in external technology acquisition could create an external dependence (Rothaermel et al. 2006), which prevents firms from developing their own internal R\&D and absorbing external knowledge.

Firms frequently use multiple strategies at the same time and this fact has barely been analyzed by OI scholars. Open innovation is not just a single strategy of external technology access, but a framework for multiple strategies. We consider that an OI framework must cover different strategies because each strategy has its own features. Hence, this paper focused on the combination of the breadth of two main strategies used by Spanish firms: cooperation and R\&D outsourcing. We proposed that a positive moderator role of cooperation breadth in the relationship between R\&D outsourcing breadth and innovation performance. Grimpe and Kaiser (2010) tested that the relationship between R\&D outsourcing intensity and innovation performance is positively moderated by the breadth of formal R\&D collaborations. We went a step further since our model considered both strategies in terms of breadth. Hence, we argued that cooperation breadth moderates the relationship between R\&D outsourcing breadth and innovation performance through two mechanisms: absorptive capacity and relational capital. We found that cooperation moderates positively that relationship, but not in all situations. It was only true for medium to high levels of $R \& D$ outsourcing breadth. When firms develop the capacities to simultaneously manage different OI strategies, they are able to benefit from the breadth of both strategies. The synergetic effect of the joint adoption of cooperation breadth and R\&D outsourcing breadth allow firms to improve innovation outcomes. The negative effect of cooperation between low and medium levels of R\&D outsourcing breadth could be due to a dynamic in which the lower transactions costs of R\&D outsourcing breadth 
make it a viable option that outweighs the benefits of diverse tacit knowledge from cooperation, though with higher cooperation costs due to co-specialized asset investments and coordination and control costs. Cooperation breadth and R\&D outsourcing breadth require a different management approach. Therefore, it provokes a substitutive effect between OI strategies. Another explanation could be that between low and medium levels of R\&D outsourcing breadth, it is difficult to build shared relational capital from cooperation breadth because common relationships are less likely to be found and these strategies are therefore substitutes.

The results of our control variables suggest that the older the firm, the more reluctant it is to introduce new products. This can be explained by the fact that older firms tend to focus solely on mature areas in which they have extensive knowledge, rather than seeking out innovative opportunities (Tsai, Hsieh and Hultink 2011). The extent of innovative performance is also dependent on the industry sector; in particular, it is more intense for electronic equipment and information systems.

\section{Conclusion}

This study focused on two different OI strategies - cooperation breadth and R\&D outsourcing breadth—, and empirically analyzed the relationship between R\&D outsourcing breadth and innovation performance, and the moderator role of cooperation breadth on that relationship, in order to explain the synergetic impact of its combination. By studying breadth in R\&D outsourcing and the moderator role of cooperation, we contribute to the OI literature in the following ways. First, literature has mainly studied breadth in cooperative activities. This study measured R\&D outsourcing in terms of breadth, in an analogous manner to that used for cooperation breadth. We found that R\&D outsourcing breadth formed an inverted-U relationship with innovative performance. Second, our paper offers another perspective with 
regard to the traditional 'buy', 'make' or 'ally' trade-off. While previous research has addressed their single impact on innovation performance (e.g. Laursen and Salter 2006; Leiponen and Helfat 2010), we compared and combined both R\&D strategies-cooperation breadth and R\&D outsourcing breadth - in a same model. Firms use different strategies at the same time, but empirical research barely analyze the interaction effect between strategies. A significant contribution of this paper is the study of the interrelationships between outsourcing and cooperation. Measuring both variables in terms of breadth allow us to discover the synergies between them. Our findings revealed that the impact of cooperation breadth on the relationship between $R \& D$ outsourcing breadth and innovation performance depends on the level of $R \& D$ outsourcing breadth. The combination of these strategies has a negative effect on innovation performance between low and medium levels of R\&D outsourcing breadth because these strategies might be substitutes. However, between medium to high levels of R\&D outsourcing breadth, cooperation exerts a positive effect because firms build relational capital that can be used by both strategies, generating economies of scale and scope. Future research literature should consider not only the combination of OI strategies, but also the level of breadth of each strategy.

This study has also some implications for practitioners. First, it is clear that the positive impact of OI strategies for innovation outcome, and thus R\&D external relationships, must be an integral part of the business model for new product development. Nevertheless, we have evidenced an inverted U-shaped relation between R\&D outsourcing breadth and innovation performance, so managers should not surpass a certain level of R\&D outsourcing breadth. Doing so increases the risk of external dependence, blocks the creation of firms' knowledge base and hampers the firms' absorptive capacity, and as a result, harms the innovation outcome. Next, the interaction of different OI strategies does not always exhibit complementarities. As our research shows, there is a potential for diseconomies in OI 
combining deployment between low to medium levels of outsourcing breadth. Hence, it may take time for managers to develop capacities to deal with a combination of OI strategies because of the costs and managerial capacities needed to deal with a joint adoption of different innovation strategies. Finally, in an era of open innovation, policy makers should also design targeted policies that boost knowledge flows between firms. Currently, incentives for collaboration are given to big and high-intensive R\&D firms (Barge-Gil 2010), but policies should also be focused on small and medium firms because we found that these kind of firms are more innovative and they are also implementing OI strategies.

Although this study reveals some interesting points, it has several limitations. First, the analysis of secondary data, such as PITEC, does not let the researcher take into account observations other than those included in the externally pre-established questionnaire. The use of primary data would have introduced the benefits of direct observational methods research (Laursen and Salter 2006). In particular, we compared OI strategies breadths basing our arguments on costs, asset specificity, type of knowledge and learning considerations, but these characteristics could not be directly observed. Using a questionnaire would improve the analysis of different OI strategies, and other constructs could be used to measure these variables. In the same manner, we considered a restrictive definition of relational capital because PITEC did not provide information for a broader concept, such as the one used in Capello and Faggian (2005). Second, we have examined R\&D outcomes through a percentage of new products as related to turnover. Future research could consider other innovative performances, such as process innovation or focus on the distinction between incremental and radical innovations. Third, PITEC has been anonymized to avoid the identification of firms. This limits our analyses as we could only consider pooled data. Fourth, our goal was not meant to be exhaustive in our discussion of inbound OI strategies, although it would have been possible to make more fine-grained, within-category distinctions. For example, some 
studies (Tsai and Wang 2009), also include licensing as a market procurement practice, but our data do not provide information about the breadth of licenses. Fifth, it would be desirable to use sampling frames other than just Spanish firms to extend the validity of the findings.

Lastly, this study also raises some interesting issues for future research. When firms embrace OI strategies they should consider not only the benefits associated with them but also their drawbacks. In particular, companies should ask themselves whether they have the resources and organizational capabilities to manage not only a particular strategy, but several strategies at the same time. Firms' deficiencies in successfully managing OI strategies underscore the need to develop organizational capabilities. These capacities may be complementary when firms combine OI strategies. Research on the joint adoption of OI strategies is almost nonexistent. Thereby, one fruitful area for future research may be to focus on factors that may be complementary to OI strategies.

\section{Acknowledgments}

The authors would like to thank the National Programs FPU from the Spanish Ministry of Education (Ref. FPU 2013/01259) and Fundamental Research Projects from the Spanish Ministry of Economy for supporting this research (Ref. ECO2013-44816-R); and INE and FECYT for allowing data access.

\section{References}

Almirall, Esteve, and Ramon Casadesus-Masanell. 2010. “Open Versus Closed Innovation: A Model of Discovery and Divergence.” Academy of Management Review 35 (1): 27-47.

Andries, Petra, and Susanne Thorwarth. 2014. "Should Firms Outsource Their Basic Research? The Impact of Firm Size on In-House versus Outsourced R\&D Productivity.” Creativity and Innovation Management 23 (3): 303-17. doi:10.1111/caim.12073. 
Audretsch, David B., Albert J. Menkveld, and A. Roy Thurik. 1996. "The Decision Between Internal and External R \& D.” Journal of Institutional and Theoretical Economics (JITE) / Zeitschrift Für Die Gesamte Staatswissenschaft 152 (3): 519-30.

Bahemia, Hanna, and Brian Squire. 2010. "A Contingent Perspective Of Open Innovation In New Product Development Projects.” International Journal of Innovation Management (ijim) 14 (04): 603-27.

Baloh, Peter, Sanjeev Jha, and Yukika Awazu. 2008. "Building Strategic Partnerships for Managing Innovation Outsourcing." Strategic Outsourcing: An International Journal 1 (2): 100-121. doi:10.1108/17538290810897138.

Barge-Gil, Andrés. 2010. “Open, Semi-Open and Closed Innovators: Towards an Explanation of Degree of Openness." Industry and Innovation 17 (6): 577-607. doi:10.1080/13662716.2010.530839.

Baum, Joel A. C., Robin Cowan, and Nicolas Jonard. 2010. "Network-Independent Partner Selection and the Evolution of Innovation Networks." Management Science 56 (11): 20942110. doi:10.1287/mnsc.1100.1229.

Baum, Joel A. C., and Brian S. Silverman. 2004. "Picking Winners or Building Them? Alliance, Intellectual, and Human Capital as Selection Criteria in Venture Financing and Performance of Biotechnology Startups.” Journal of Business Venturing, Evolutionary approaches to entrepreneurship: Honoring Howard Aldrich, 19 (3): 411-36. doi:10.1016/S0883-9026(03)00038-7.

Belderbos, René, Martin Carree, and Boris Lokshin. 2004. "Cooperative R\&D and Firm Performance.” Research Policy 33 (10): 1477-92. doi:10.1016/j.respol.2004.07.003.

Berchicci, Luca. 2013. "Towards an Open R\&D System: Internal R\&D Investment, External Knowledge Acquisition and Innovative Performance." Research Policy 42 (1): 117-27. doi:10.1016/j.respol.2012.04.017. 
Capello, Roberta, and Alessandra Faggian. 2005. "Collective Learning and Relational Capital in Local Innovation Processes." Regional Studies 39 (1): 75-87. doi:10.1080/0034340052000320851.

Cassiman, Bruno, and Reinhilde Veugelers. 2002. "Complementarity in the Innovation Strategy: Internal R\&D, External Technology Acquisition and Cooperation." SSRN Scholarly Paper ID 308601. Rochester, NY: Social Science Research Network. http://papers.ssrn.com/abstract=308601.

. 2006. "In Search of Complementarity in Innovation Strategy: Internal R\&D and External Knowledge Acquisition." Management Science 52 (1): 68-82. doi:10.1287/mnsc.1050.0470.

Chesbrough, Henry. 2012. “Open Innovation: Where We've Been and Where We're Going." Research-Technology Management 55 (4): 20-27. doi:10.5437/08956308X5504085.

Chesbrough, Henry, and Melissa Appleyard. 2007. "Open Innovation and Strategy." Business Administration Faculty Publications and Presentations. http://pdxscholar.library.pdx.edu/busadmin_fac/23.

Chesbrough, Henry, and Marcel Bogers. 2014. "Explicating Open Innovation: Clarifying an Emerging Paradigm for Understanding Innovation.” In New Frontiers in Open Innovation, by Henry Chesbrough, W. Vanhaverbeke, and Joel West. Oxford: Oxford University Press.

Cohen, Wesley M., and Daniel A. Levinthal. 1990. “Absorptive Capacity: A New Perspective on Learning and Innovation." Administrative Science Quarterly 35 (1): 128-52. doi:10.2307/2393553.

Cohen, Wesley M., Richard R. Nelson, and John P. Walsh. 2002. "Links and Impacts: The Influence of Public Research on Industrial R\&D.” Management Science 48 (1): 1-23. doi:10.1287/mnsc.48.1.1.14273. 
Collins, Jamie, and Jason Riley. 2013. “Alliance Portfolio Diversity and Firm Performance: Examining Moderators.” Journal of Business and Management 19 (2): 35-50.

Cui, Zhijian, Christoph Loch, Bernd Grossmann, and Ru He. 2012. "How Provider Selection and Management Contribute to Successful Innovation Outsourcing: An Empirical Study at Siemens." Production and Operations Management 21 (1): 29-48. doi:10.1111/j.19375956.2011.01237.x.

Dahlander, Linus, and David M. Gann. 2010. "How Open Is Innovation?” Research Policy 39 (6): 699-709. doi:10.1016/j.respol.2010.01.013.

Dhont-Peltrault, Estelle, and Etienne Pfister. 2011. "R\&D Cooperation versus R\&D Subcontracting: Empirical Evidence from French Survey Data.” Economics of Innovation and New Technology 20 (4): 309-341. doi:10.1080/10438591003669743.

Escribano, Alvaro, Andrea Fosfuri, and Josep A. Tribó. 2009. "Managing External Knowledge Flows: The Moderating Role of Absorptive Capacity." Research Policy 38 (1): 96-105. doi:10.1016/j.respol.2008.10.022.

Faems, Dries, Matthias De Visser, Petra Andries, and Bart Van Looy. 2010. "Technology Alliance Portfolios and Financial Performance: Value-Enhancing and Cost-Increasing Effects of Open Innovation*." Journal of Product Innovation Management 27 (6): 785-96. doi:10.1111/j.1540-5885.2010.00752.x.

Faems, Dries, Bart Van Looy, and Koenraad Debackere. 2005. "Interorganizational Collaboration and Innovation: Toward a Portfolio Approach*." Journal of Product Innovation Management 22 (3): 238-50. doi:10.1111/j.0737-6782.2005.00120.x.

Fey, Carl F., and Julian Birkinshaw. 2005. "External Sources of Knowledge, Governance Mode, and R\&D Performance." Journal of Management 31 (4): 597-621. doi:10.1177/0149206304272346. 
Friedrich, Robert J. 1982. "In Defense of Multiplicative Terms in Multiple Regression Equations.” American Journal of Political Science 26 (4): 797-833. doi:10.2307/2110973. Gassmann, Oliver, Ellen Enkel, and Henry Chesbrough. 2010. "The Future of Open Innovation.” R\&D Management 40 (3): 213-21. doi:10.1111/j.1467-9310.2010.00605.x.

Gilley, K. Matthew, and Abdul Rasheed. 2000. "Making More by Doing Less: An Analysis of Outsourcing and Its Effects on Firm Performance.” Journal of Management 26 (4): $763-$ 90. doi:10.1177/014920630002600408.

Gooroochurn, Nishaal, and Aoife Hanley. 2007. “A Tale of Two Literatures: Transaction Costs and Property Rights in Innovation Outsourcing.” Research Policy 36 (10): 1483-95. doi:10.1016/j.respol.2007.07.001.

Grimpe, Christoph, and Ulrich Kaiser. 2010. "Balancing Internal and External Knowledge Acquisition: The Gains and Pains from R\&D Outsourcing." Journal of Management Studies 47 (8): 1483-1509. doi:10.1111/j.1467-6486.2010.00946.x.

Gulati, Ranjay. 1998. “Alliances and Networks.” Strategic Management Journal 19 (4): 293317. doi:10.1002/(SICI)1097-0266(199804)19:4<293::AID-SMJ982>3.0.CO;2-M.

Hagedoorn, John. 1993. "Understanding the Rationale of Strategic Technology Partnering: Nterorganizational Modes of Cooperation and Sectoral Differences." Strategic Management Journal 14 (5): 371-85. doi:10.1002/smj.4250140505.

Hagedoorn, John, and Geerte Hesen. 2007. "Contract Law and the Governance of Inter-Firm Technology Partnerships - An Analysis of Different Modes of Partnering and Their Contractual Implications*." Journal of Management Studies 44 (3): 342-66. doi:10.1111/j.1467-6486.2006.00679.x.

Hagedoorn, John, and Ning Wang. 2012. "Is There Complementarity or Substitutability between Internal and External R\&D Strategies?” Research Policy, Special Section on Sustainability Transitions, 41 (6): 1072-83. doi:10.1016/j.respol.2012.02.012. 
Heckman, James J. 1979. "Sample Selection Bias as a Specification Error.” Econometrica 47 (1): 153. doi:10.2307/1912352.

Hoecht, A., and P. Trott. 2006. "Innovation Risks of Strategic Outsourcing." Technovation 26 (5-6): 672-81. doi:10.1016/j.technovation.2005.02.004.

Holl, Adelheid, and Ruth Rama. 2014. "Foreign Subsidiaries and Technology Sourcing in Spain.” Industry and Innovation 21(1): 43-64. doi:10.1080/13662716.2014.879254

Holmstrom, Bengt. 1989. "Agency Costs and Innovation.” Journal of Economic Behavior \& Organization 12 (3): 305-27. doi:10.1016/0167-2681(89)90025-5.

Howells, Jeremy, Dimitri Gagliardi, and Khaleel Malik. 2008. "The Growth and Management of R\&D Outsourcing: Evidence from UK Pharmaceuticals." $R \& D$ Management 38 (2): 205-19. doi:10.1111/j.1467-9310.2008.00508.x.

Kale, Prashant, Jeffrey H. Dyer, and Harbir Singh. 2002. "Alliance Capability, Stock Market Response, and Long-Term Alliance Success: The Role of the Alliance Function.” Strategic Management Journal 23 (8): 747-67. doi:10.1002/smj.248.

Kale, Prashant, and Harbir Singh. 2007. "Building Firm Capabilities through Learning: The Role of the Alliance Learning Process in Alliance Capability and Firm-Level Alliance Success.” Strategic Management Journal 28 (10): 981-1000. doi:10.1002/smj.616.

. 2009. "Managing Strategic Alliances: What Do We Know Now, and Where Do We Go From Here?" The Academy of Management Perspectives 23 (3): 45-62. doi:10.5465/AMP.2009.43479263.

Kale, Prashant, Harbir Singh, and Howard Perlmutter. 2000. "Learning and Protection of Proprietary Assets in Strategic Alliances: Building Relational Capital.” Strategic Management Journal $21 \quad$ (3): 217-37. doi:10.1002/(SICI)10970266(200003)21:3<217::AID-SMJ95>3.0.CO;2-Y. 
Khanna, Tarun, Ranjay Gulati, and Nitin Nohria. 1998. "The Dynamics of Learning Alliances: Competition, Cooperation, and Relative Scope." Strategic Management Journal 19 (3): 193-210.

Kotabe, Masaaki, and Michael J. Mol. 2009. "Outsourcing and Financial Performance: A Negative Curvilinear Effect.” Journal of Purchasing and Supply Management 15 (4): 20513. doi:10.1016/j.pursup.2009.04.001.

Kotabe, Masaaki, Michael J. Mol, Janet Y. Murray, and Ronaldo Parente. 2012. "Outsourcing and Its Implications for Market Success: Negative Curvilinearity, Firm Resources, and Competition." Journal of the Academy of Marketing Science 40 (2): 329-46. doi:10.1007/s11747-011-0276-z.

Lane, P. J., and M. Lubatkin. 1998. "Relative Absorptive Capacity and Interorganizational Learning.” Strategic Management Journal 19 (5): 461-77.

Laursen, Keld, and Ammon Salter. 2006. "Open for Innovation: The Role of Openness in Explaining Innovation Performance among U.K. Manufacturing Firms.” Strategic Management Journal 27 (2): 131-50. doi:10.1002/smj.507.

Leachman, Chien, C. Carl Pegels, and Seung Kyoon Shin. 2005. "Manufacturing Performance: Evaluation and Determinants." International Journal of Operations \& Production Management 25 (9): 851-74. doi:10.1108/01443570510613938.

Leeuw, Tim, Boris Lokshin, and Geert Duysters. 2014. "Returns to Alliance Portfolio Diversity: The Relative Effects of Partner Diversity on Firm's Innovative Performance and Productivity." Journal of Business Research $67 \quad$ (9): 1839-49. doi:10.1016/j.jbusres.2013.12.005.

Leiponen, Aija, and Constance E. Helfat. 2010. "Innovation Objectives, Knowledge Sources, and the Benefits of Breadth." Strategic Management Journal 31 (2): 224-36. doi:10.1002/smj.807. 
Lin, Eric S., Yi-Chi Hsiao, and Hui-lin Lin. 2013. "Complementarities of R\&D Strategies on Innovation Performance: Evidence from Taiwanese Manufacturing Firms." Technological and Economic Development of Economy 19(sup1): S134-S156. doi:10.3846/20294913.2013.876684.

Lokshin, Boris, René Belderbos, and Martin Carree. 2008. "The Productivity Effects of Internal and External R\&D: Evidence from a Dynamic Panel Data Model*." Oxford Bulletin of Economics and Statistics 70 (3): 399-413. doi:10.1111/j.14680084.2008.00503.x.

López, Alberto. 2011. "The Effect of Microaggregation on Regression Results: An Application to Spanish Innovation Data." MRPA Paper. https://mpra.ub.unimuenchen.de/30403/.

Love, James H., and Stephen Roper. 2001. "Outsourcing in the Innovation Process: Locational and Strategic Determinants." Papers in Regional Science 80 (3): 317-36. doi:10.1111/j.1435-5597.2001.tb01802.x.

. 2009. "Organizing the Innovation Process: Complementarities in Innovation Networking." Industry and Innovation 16 (3): 273-90. doi:10.1080/13662710902923776.

Luker, William, and Donald Lyons. 1997. "Employment Shifts in High-Technology Industries, 1988-96." Monthly Labor Review 120 (6): 12-25.

McIvor, Ronan. 2009. "How the Transaction Cost and Resource-Based Theories of the Firm Inform Outsourcing Evaluation." Journal of Operations Management 27 (1): 45-63. doi:10.1016/j.jom.2008.03.004.

Mitsuhashi, Hitoshi, and Henrich R. Greve. 2009. “A Matching Theory of Alliance Formation and Organizational Success: Complementarity and Compatibility." Academy of Management Journal 52 (5): 975-95. doi:10.5465/AMJ.2009.44634482. 
Mudambi, Susan M., and Stephen Tallman. 2010. "Make, Buy or Ally? Theoretical Perspectives on Knowledge Process Outsourcing through Alliances." Journal of Management Studies 47 (8): 1434-56. doi:10.1111/j.1467-6486.2010.00944.x.

Narula, Rajneesh. 2001. “Choosing Between Internal and Non-Internal R\&D Activities: Some Technological and Economic Factors." Technology Analysis \& Strategic Management 13 (3): 365-87. doi:10.1080/09537320120088183.

Nieto, María Jesús, and Lluis Santamaría. 2007. "The Importance of Diverse Collaborative Networks for the Novelty of Product Innovation." Technovation 27 (6-7): 367-77. doi:10.1016/j.technovation.2006.10.001.

OECD. 2005. Oslo Manual: Guidelines for Collecting and Interpreting Innovation Data. 3rd ed. Paris: Organisation for Economic Co-operation and Development.

Oerlemans, L. A. G., J. Knoben, and M. W. Pretorius. 2013. "Alliance Portfolio Diversity, Radical and Incremental Innovation: The Moderating Role of Technology Management.” Technovation 33 (6-7): 234-46. doi:10.1016/j.technovation.2013.02.004.

Oxley, Joanne E. 1997. “Appropriability Hazards and Governance in Strategic Alliances: A Transaction Cost Approach.” Journal of Law, Economics, and Organization 13 (2): $387-$ 409.

Piga, C., and M. Vivarelli. 2003. "Sample Selection in Estimating the Determinants of Cooperative R\&D.” Applied Economics Letters $10 \quad$ (4): 243-46. doi:10.1080/1350485022000044156.

—. 2004. "Internal and External R\&D: A Sample Selection Approach*." Oxford Bulletin of Economics and Statistics 66 (4): 457-482. doi:10.1111/j.1468-0084.2004.00089.x.

Poppo, Laura, and Todd Zenger. 2002. "Do Formal Contracts and Relational Governance Function as Substitutes or Complements?” Strategic Management Journal 23 (8): 707-25. doi:10.1002/smj.249. 
Rothaermel, Frank T., and David L. Deeds. 2006. "Alliance Type, Alliance Experience and Alliance Management Capability in High-Technology Ventures." Journal of Business Venturing, Entrepreneurship and Strategic Alliances, 21 (4): 429-60. doi:10.1016/j.jbusvent.2005.02.006.

Rothaermel, Frank T., Michael A. Hitt, and Lloyd A. Jobe. 2006. "Balancing Vertical Integration and Strategic Outsourcing: Effects on Product Portfolio, Product Success, and Firm Performance." Strategic Management Journal 27 (11): 1033-56. doi:10.1002/smj.559.

Rundquist, Jonas, and Fawzi Halila. 2010. "Outsourcing of NPD Activities: A Best Practice Approach.” European Journal of Innovation Management 13 (1): 5-23. doi:http://0dx.doi.org.cisne.sim.ucm.es/10.1108/14601061011013203.

Sampson, Rachelle C. 2005. "Experience Effects and Collaborative Returns in R\&D Alliances.” Strategic Management Journal 26 (11): 1009-31. doi:10.1002/smj.483.

Sandulli, Francesco D., Jose Fernandez-Menendez, Antonio Rodriguez-Duarte, and José Ignacio Lopez-Sanchez. 2012. "Testing the Schumpeterian Hypotheses on an Open Innovation Framework.” Management Decision $50 \quad$ (7): 1222-32. doi:10.1108/00251741211246978.

Schilke, Oliver, and Anthony Goerzen. 2010. "Alliance Management Capability: An Investigation of the Construct and Its Measurement." Journal of Management 36 (5): 1192-1219. doi:10.1177/0149206310362102.

Schmiedeberg, Claudia. 2008. "Complementarities of Innovation Activities: An Empirical Analysis of the German Manufacturing Sector." Research Policy 37(9): 1492-1503. doi:10.1016/j.respol.2008.07.008

Sen, A., and A. MacPherson. 2009. "Outsourcing, Externa Collaboration, and Innovation among US Firms in the Biopharmaceutical Industry.” Industrial Geographer 6 (1): 20-36. 
Spithoven, André, Bart Clarysse, and Mirjam Knockaert. 2011. "Building Absorptive Capacity to Organise Inbound Open Innovation in Traditional Industries.” Technovation 31 (1): 10-21. doi:10.1016/j.technovation.2010.10.003.

Spithoven, André, and Peter Teirlinck. 2015. "Internal Capabilities, Network Resources and Appropriation Mechanisms as Determinants of R\&D Outsourcing." Research Policy 44 (3): 711-25. doi:10.1016/j.respol.2014.10.013.

Stanko, Michael A., and Xavier Olleros. 2013. "Industry Growth and the Knowledge Spillover Regime: Does Outsourcing Harm Innovativeness but Help Profit?” Journal of Business Research, 66 (10): 2007-16. doi:10.1016/j.jbusres.2013.02.026.

Teirlinck, Peter, Michel Dumont, and André Spithoven. 2010. "Corporate Decision-Making in R\&D Outsourcing and the Impact on Internal R\&D Employment Intensity." Industrial and Corporate Change 19 (6): 1741-68. doi:10.1093/icc/dtq038.

Teirlinck, Peter, and André Spithoven. 2008. "The Spatial Organization of Innovation: Open Innovation, External Knowledge Relations and Urban Structure.” Regional Studies 42 (5): 689-704. doi:10.1080/00343400701543694.

. 2011. "Formal R\&d Management and Research Collaboration and R\&D Outsourcing in SMEs." Proceedings of the 6th European Conference on Innovation and Entrepreneurship: 820-26. Aberdeen Business School.

. 2013. "Research Collaboration and R\&D Outsourcing: Different R\&D Personnel Requirements in SMEs.” Technovation $33 \quad$ (4-5): 142-53. doi:10.1016/j.technovation.2012.11.005.

Tobin, J. 1958. "Estimation of Relationships for Limited Dependent Variables." Econometrica 26: 24-36. doi:10.2307/1907382.

Trombini, Giulia, and Anna Comacchio. 2012. "Cooperative Markets for Ideas: When Does Technology Licensing Combine with R\&D Partnerships?” Working Paper 8. Department 
of Management, Università Ca’ Foscari http://econpapers.repec.org/paper/vnmwpdman/21.htm.

Tsai, Kuen-Hung. 2009. “Collaborative Networks and Product Innovation Performance: Toward a Contingency Perspective.” Research Policy 38 (5): 765-78. doi:10.1016/j.respol.2008.12.012.

Tsai, Kuen-Hung, and Ming-Hung Hsieh. 2009. "How Different Types of Partners Influence Innovative Product Sales: Does Technological Capacity Matter?” Journal of Business Research 62 (12): 1321-28. doi:10.1016/j.jbusres.2009.01.003.

Tsai, Kuen-Hung, Ming-Hung Hsieh, and Erik Jan Hultink. 2011. "External Technology Acquisition and Product Innovativeness: The Moderating Roles of R\&D Investment and Configurational Context." Journal of Engineering and Technology Management 28 (3): 184-200. doi:10.1016/j.jengtecman.2011.03.005.

Tsai, Kuen-Hung, and Jiann-Chyuan Wang. 2008. "External Technology Acquisition and Firm Performance: A Longitudinal Study.” Journal of Business Venturing 23 (1): 91-112. doi:10.1016/j.jbusvent.2005.07.002.

—. 2009. "External Technology Sourcing and Innovation Performance in LMT Sectors: An Analysis Based on the Taiwanese Technological Innovation Survey.” Research Policy, Special Issue: Innovation in Low-and Meduim-Technology Industries, 38 (3): 518-26. doi:10.1016/j.respol.2008.10.007.

Un, C. Annique, Alvaro Cuervo-Cazurra, and Kazuhiro Asakawa. 2010. "R\&D Collaborations and Product Innovation.” Journal of Product Innovation Management 27 (5): 673-89. doi:10.1111/j.1540-5885.2010.00744.x.

Vega Jurado, Jaider, Liney Manjarrés Henríquez, and Antonio Gutiérrez Gracia. 2010. “Cooperation with Scientific Agents and Firm's Innovative Performance.” In . Aalborg (Denmark). http://digital.csic.es/handle/10261/26695. 
Veugelers, Reinhilde. 1997. "Internal R \& D Expenditures and External Technology Sourcing." Research Policy 26 (3): 303-15. doi:10.1016/S0048-7333(97)00019-X.

Veugelers, Reinhilde, and Bruno Cassiman. 1999. "Make and Buy in Innovation Strategies: Evidence from Belgian Manufacturing Firms." Research Policy 28 (1): 63-80. doi:10.1016/S0048-7333(98)00106-1.

Wang, Yuandi, and Jason Li-Ying. 2014. "When Does Inward Technology Licensing Facilitate Firms' NPD Performance? A Contingency Perspective.” Technovation 34 (1): 44-53. doi:10.1016/j.technovation.2013.09.002.

Wang, Yuandi, N. Roijakkers, and W. Vanhaverbeke. 2013. "Learning-by-Licensing: How Chinese Firms Benefit From Licensing-In Technologies." IEEE Transactions on Engineering Management 60 (1): 46-58. doi:10.1109/TEM.2012.2205578.

Weigelt, Carmen. 2009. "The Impact of Outsourcing New Technologies on Integrative Capabilities and Performance." Strategic Management Journal 30 (6): 595-616. doi:10.1002/smj.760.

Williamson, Oliver E. 1991. "Comparative Economic Organization: The Analysis of Discrete Structural Alternatives." Administrative Science Quarterly 36 (2): 269. doi:10.2307/2393356.

Zobel, Ann-Kristin. 2013. "Open Innovation: A Dynamic Capabilities Perspective." Maastricht: Maastricht University.

\section{Appendices}

\section{Table 1.}

R\&D outsourcing and cooperation features

\begin{tabular}{l|ll}
\hline Dimension & R\&D Outsourcing & Cooperation \\
\hline Relationship duration & Short-term relationship & Medium- or long-term relationship \\
Knowledge & Explicit & Tacit \\
Learning & Low & High \\
Transaction costs & Low - medium & Medium - high \\
Asset specificity & Low & High \\
\hline
\end{tabular}


Source: Own elaboration.

Table 2.

Variable description

\begin{tabular}{|c|c|c|}
\hline Variable & Description & References \\
\hline Newprod & $\begin{array}{l}\text { Proportion relative to turnover of new or strongly } \\
\text { improved products that the company introduced } \\
\text { to the market and that were new to the market or } \\
\text { to the firm. }\end{array}$ & $\begin{array}{l}\text { Belderbos et al. (2004); } \\
\text { Faems et al. (2005, 2010); } \\
\text { Nieto and Santamaria (2007) }\end{array}$ \\
\hline Coop & $\begin{array}{l}\text { Addition of seven sources of collaboration: } \\
\text { suppliers, customers, public sector customers, } \\
\text { competitors, consultants, universities, and } \\
\text { research centers. }\end{array}$ & Laursen and Salter (2006) \\
\hline Out & $\begin{array}{l}\text { Addition of six sources of outsourcing: firms, } \\
\text { research centers, public sector, universities, no } \\
\text { governmental organizations, and other } \\
\text { international organizations. }\end{array}$ & $\begin{array}{l}\text { Extended from Laursen and } \\
\text { Salter (2006) }\end{array}$ \\
\hline Coop_out & Interaction between coop and out variables. & - \\
\hline Coop_out2 & $\begin{array}{l}\text { Interaction between coop and out square } \\
\text { variables. }\end{array}$ & - \\
\hline Age & $\begin{array}{l}\text { Natural logarithm of the number of years between } \\
\text { the foundation of the firm and the observation } \\
\text { year. }\end{array}$ & $\begin{array}{l}\text { Tsai et al. (2011); Wang et al. } \\
\text { (2013); Wang and Li-Ying } \\
\text { (2014) }\end{array}$ \\
\hline Size & $\begin{array}{l}\text { Natural logarithm of the total number of } \\
\text { employees. }\end{array}$ & $\begin{array}{l}\text { Berchicci (2013); Cassiman } \\
\text { and Veugelers (2002) }\end{array}$ \\
\hline Intrd & Proportion of firm's internal innovation expenses. & $\begin{array}{l}\text { Lin et al. (2013); } \\
\text { Schmiedeberg }(2008)\end{array}$ \\
\hline Pat & Dummy variable for firm's application of patents. & Faems et al. (2005) \\
\hline Outintensity & Share of $R \& D$ external expenses. & Grimpe and Kaiser (2010) \\
\hline CNAE & $\begin{array}{l}\text { A set of dummy variables for our CNAE sectors, } \\
\text { the Spanish equivalent of SIC codes. }\end{array}$ & Un et al. (2010) \\
\hline Year & $\begin{array}{l}\text { A set of dummy variables for the observation } \\
\text { year. }\end{array}$ & $\begin{array}{l}\text { Un et al. (2010); Wang et al. } \\
\text { (2013) }\end{array}$ \\
\hline
\end{tabular}

Table 3

Means and standard deviations of major variables used in the analysis

\begin{tabular}{lccccccccc}
\hline \multicolumn{1}{c}{ Year } & 2004 & 2005 & 2006 & 2007 & 2008 & 2009 & 2010 & 2011 & 2012 \\
\hline Obs. & 5,506 & 7,503 & 7,519 & 7,325 & 7,158 & 7,112 & 7,069 & 6,310 & 5,932 \\
Newprod & 22.22 & 28.04 & 26.58 & 26.08 & 28.42 & 28.77 & 28.93 & 25.77 & 22.78 \\
& $(32.29)$ & $(37.16)$ & $(36.26)$ & $(35.99)$ & $(37.03)$ & $(36.98)$ & $(37.04)$ & $(36.20)$ & $(34.62)$ \\
Coop & 0.89 & 0.79 & 0.81 & 0.83 & 0.88 & 0.9 & 0.95 & 1.01 & 1.02 \\
& $(1.53)$ & $(1.44)$ & $(1.49)$ & $(1.55)$ & $(1.58)$ & $(1.62)$ & $(1.68)$ & $(1.75)$ & $(1.70)$ \\
Out & 0.51 & 0.44 & 0.44 & 0.44 & 0.42 & 0.41 & 0.41 & 0.44 & 0.43 \\
& $(0.77)$ & $(0.74)$ & $(0.75)$ & $(0.77)$ & $(0.77)$ & $(0.77)$ & $(0.78)$ & $(0.80)$ & $(0.81)$ \\
Age & 22.49 & 21.7 & 22.65 & 23.79 & 25.07 & 26.22 & 27.32 & 28.46 & 29.46 \\
& $(19.91)$ & $(19.76)$ & $(19.76)$ & $(20.02)$ & $(20.51)$ & $(20.61)$ & $(20.64)$ & $(21.00)$ & $(20.81)$ \\
Size & 304.39 & 263.70 & 282.76 & 307.74 & 322.24 & 327.90 & 331.56 & 357.95 & 358.72 \\
& $(1322.62)$ & $(1191.11)$ & $(1308.41)$ & $(1493.45)$ & $(1555.89)$ & $(1637.40)$ & $(1576.09)$ & $(1699.63)$ & $(1769.78)$ \\
Pat & 0.21 & 0.15 & 0.14 & 0.14 & 0.13 & 0.13 & 0.13 & 0.13 & 0.13 \\
& $(0.40)$ & $(0.36)$ & $(0.35)$ & $(0.34)$ & $(0.34)$ & $(0.33)$ & $(0.33)$ & $(0.34)$ & $(0.34)$ \\
Intrd & 65.80 & 59.25 & 54.82 & 52.65 & 52.07 & 49.21 & 47.26 & 51.94 & 54.77 \\
& $(40.68)$ & $(39.64)$ & $(42.35)$ & $(42.01)$ & $(42.40)$ & $(42.61)$ & $(42.88)$ & $(43.03)$ & $(43.12)$ \\
Outintensity & 14.56 & 9.34 & 10.14 & 10.20 & 9.79 & 9.48 & 9.12 & 9.54 & 9.00
\end{tabular}




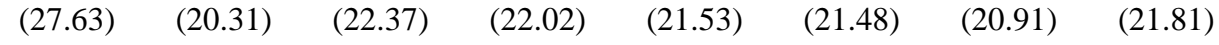

Note: The figures in parentheses are standard deviations.

Table 4.

Correlation coefficients of major variables used in the model

\begin{tabular}{|c|c|c|c|c|c|c|c|}
\hline & Newprod & Coop & Out & Logage & Logsize & Pat & Intrd \\
\hline \multicolumn{8}{|l|}{$\begin{array}{l}\text { Newprod } \\
\text { p-value }\end{array}$} \\
\hline Coop & 0.088 & & & & & & \\
\hline$p$-value & 0.000 & & & & & & \\
\hline Out & 0.047 & 0.408 & & & & & \\
\hline$p$-value & 0.000 & 0.000 & & & & & \\
\hline Logage & -0.102 & -0.006 & 0.022 & & & & \\
\hline$p$-value & 0.000 & 0.131 & 0.000 & & & & \\
\hline Logsize & -0.077 & 0.145 & 0.108 & 0.376 & & & \\
\hline$p$-value & 0.000 & 0.000 & 0.000 & 0.000 & & & \\
\hline Pat & 0.089 & 0.212 & 0.213 & -0.008 & 0.062 & & \\
\hline p-value & 0.000 & 0.000 & 0.000 & 0.043 & 0.000 & & \\
\hline Intrd & 0.111 & 0.168 & 0.089 & -0.073 & -0.073 & 0.143 & \\
\hline$p$-value & 0.000 & 0.000 & 0.000 & 0.000 & 0.000 & 0.000 & \\
\hline Outintensity & -0.003 & 0.104 & 0.459 & 0.015 & 0.051 & 0.041 & -0.214 \\
\hline p-value & 0.402 & 0.000 & 0.000 & 0.000 & 0.000 & 0.000 & 0.000 \\
\hline
\end{tabular}

Note: This table omits the correlation coefficients of industry and time-effect dummies.

Table 5.

Tobit regression, explaining innovation performance across Spain firms.

\begin{tabular}{|c|c|c|c|c|c|c|}
\hline Model & $\mathrm{I}$ & & II & & III & \\
\hline Indepen Var. & Coef. & Std. Err. & Coef. & Std. Err. & Coef. & Std. Err. \\
\hline Logage & $-0.199 * * *$ & 0.020 & $-0.187 * * *$ & 0.020 & $-0.188 * * *$ & 0.020 \\
\hline Logsize & 0.010 & 0.009 & $-0.039 * * *$ & 0.010 & $-0.039 * * *$ & 0.010 \\
\hline Pat & $1.017 * * *$ & 0.038 & $0.817 * * *$ & 0.038 & $0.815^{* * * *}$ & 0.038 \\
\hline Intrd & $0.011 * * *$ & 0.000 & $0.009 * * *$ & 0.000 & $0.008 * * *$ & 0.000 \\
\hline Outintensity & $0.004 * * *$ & 0.001 & $-0.003 * * *$ & 0.001 & $-0.003 * * *$ & 0.001 \\
\hline Coop & & & $0.345^{* * *}$ & 0.015 & $0.380 * * *$ & 0.016 \\
\hline Out & & & $0.402 * * *$ & 0.034 & $0.418 * * *$ & 0.038 \\
\hline Out2 & & & $-0.288 * * *$ & 0.031 & $-0.261 * * *$ & 0.039 \\
\hline Coop_Out & & & & & $-0.111 * * *$ & 0.024 \\
\hline Coop_Out2 & & & & & $0.049 * *$ & 0.021 \\
\hline $\begin{array}{l}\text { Industry } \\
\text { dummies }\end{array}$ & Yes & & Yes & & Yes & \\
\hline $\begin{array}{l}\text { Time-effect } \\
\text { dummies }\end{array}$ & Yes & & Yes & & Yes & \\
\hline _cons & 0.166 & 0.152 & $0.430 * * *$ & 0.151 & $0.450 * * *$ & 0.151 \\
\hline /sigma & 2.997 & 0.014 & 2.967 & 0.013 & 2.966 & 0.013 \\
\hline No. of obs & 61434 & & 61434 & & 61434 & \\
\hline $\begin{array}{l}\text { No. of left- } \\
\text { censored obs }\end{array}$ & 20896 & & 20896 & & 20896 & \\
\hline $\begin{array}{l}\text { No. of right- } \\
\text { censored obs }\end{array}$ & 8413 & & 8413 & & 8413 & \\
\hline $\begin{array}{c}\log \\
\text { likelihood }\end{array}$ & -107340.75 & & -106881.39 & & -106862.6 & \\
\hline Chi-square & $5814.64 * * *$ & & $6733.36 * * *$ & & $6770.95 * * *$ & \\
\hline
\end{tabular}


$\begin{array}{llll}\text { Pseudo } \mathrm{R}^{2} & 0.0264 & 0.0305 & 0.0307\end{array}$

One-tailed t-test applied. * $\mathrm{p}<0.10 ; * * \mathrm{p}<0.05 ; * * * \mathrm{p}<0.01$

\section{Figure 1.}

OI strategies for knowledge transfer

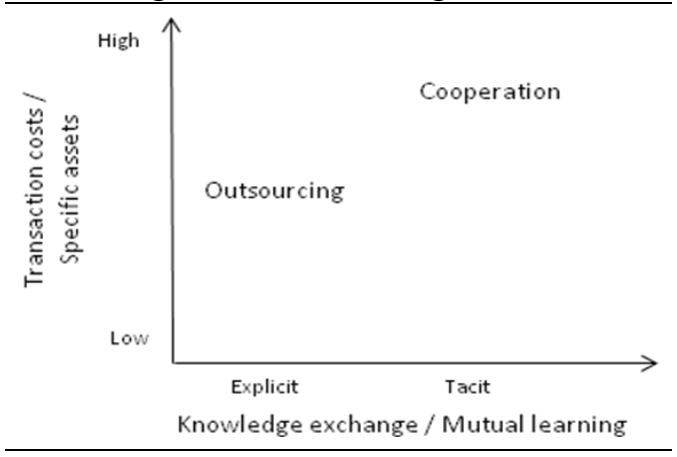

Source: Own elaboration

\section{Figure 2.}

Interactive effects between cooperation and R\&D outsourcing

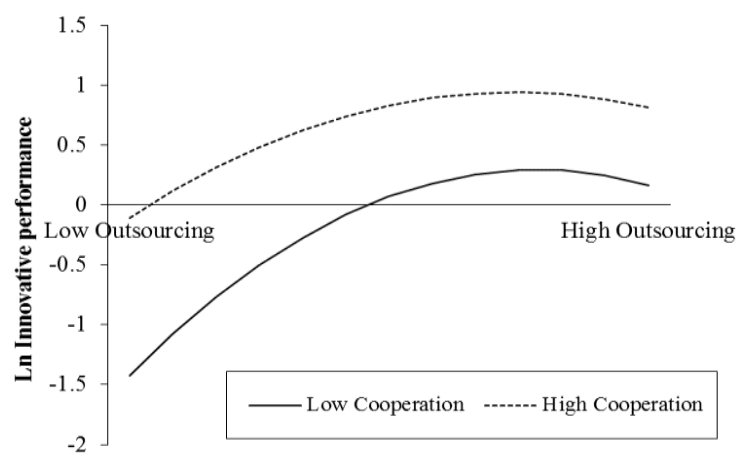

